\title{
Carbon Monoxide Oxidation on Nanostructured Pt Thin Films Synthesized by Pulsed Laser Deposition: Insights into the Morphology Effects
}

\author{
Fatma Saidani, ${ }^{1}$ Dominic Rochefort, ${ }^{2}$ and Mohamed Mohamedi ${ }^{1}$ \\ ${ }^{1}$ INRS -Énergie, Matériaux et Télécommunications (EMT), Institut National de la Recherche Scientifique (INRS), \\ 1650 Boulevard Lionel Boulet, Varennes, QC, Canada J3X 1S2 \\ ${ }^{2}$ Department of Chemistry, University of Montreal, 6128 Centre-Ville, Montreal QC, Canada H3C 3J7
}

Correspondence should be addressed to Mohamed Mohamedi, mohamedi@emt.inrs.ca

Received 23 July 2010; Accepted 25 September 2010

Academic Editor: Yoshizumi Kajii

Copyright (C) 2010 Fatma Saidani et al. This is an open access article distributed under the Creative Commons Attribution License, which permits unrestricted use, distribution, and reproduction in any medium, provided the original work is properly cited.

\begin{abstract}
Nanostructured Pt thin film catalysts of various morphologies have been synthesized by pulsed laser deposition and studied towards enhancing their tolerance to CO poisoning, a reaction of critical issue to liquid fuel cells. It was discovered that Pt film deposited under 5 Torr of He background pressure showed the highest electroactive surface area and the lowest onset potential of $\mathrm{CO}$ oxidation demonstrating an enhancement of the $\mathrm{CO}$ poisoning resistance. The reason for such enhanced electrocatalytic activity is ascribed to the high roughness of Pt surface. This study further provides a methodology for the proper design of electrocatalysts that might be considered to be developed by the pulsed laser deposition technique.
\end{abstract}

\section{Introduction}

Carbon monoxide (CO) oxidation is one of the most investigated heterogeneous reactions, being scientifically and industrially essential, principally for removal of $\mathrm{CO}$ from exhaust streams and preferential oxidation in fuel-cell applications. Within this quest, Direct Alcohol Fuel Cell (DAFC) is a promising technology for transportation and portable electronic devices, and both methanol and ethanol are strong contenders for such low-temperature fuel cells because they are hydrogen-rich liquids, they possess high energy density, and they can be produced in great quantities from biomass [1]. In spite of years of countless attempts to substitute platinum by non noble metal, the former continues to be the metal of choice to catalyze oxidation and reduction reactions occurring at the anode and cathode, respectively, of polymer electrolyte membrane fuel cells (PEMFCs) [2]. However, when used as anode catalyst, pure platinum is rapidly poisoned by strongly adsorbed $\mathrm{CO}$ coming from the dissociative adsorption of methanol or ethanol [3].

Understanding the effect of the surface structure and morphology on the electroactivity and resistance to poison- ing might help proper design of Pt with enhanced tolerance to CO poisoning. Such study has not been comprehensively performed so far. Because of their small size and large surface-to-volume ratio, nanoparticles (NPs) may lead to an increase in the catalytic efficiency, and in the mean time allow very low loading Pt catalyst to be employed.

The challenge has been always to find a better technique to obtain the highly localized of reliable particle size of high purity catalyst deposited directly at the support, which will result in extremely high catalyst utilization. The technique must also be versatile to allow investigating various morphologies of the catalyst. The pulsed laser deposition (PLD) is a physical vapour deposition technique that has emerged in the last decade as a viable means of producing high-quality thin films of a wide variety of materials, including insulators, semiconductors, high temperature superconductors, metals, and metal oxides $[4,5]$. The technique normally produces a film with the same composition as the target; it is ideally suited for the deposition of minute amount of material which is an advantage over other thin film deposition techniques. The other benefit expected from the use of PLD to prepare metal NPs is that it allows one to control the morphology 
of the deposited metal from discrete NPs to formation of a continuous film, through the surface chemistry particles as small as $2 \mathrm{~nm}$ can be obtained [6].

This work aims to use the PLD technique as a mean to prepare nanostructured Pt catalyst of various morphologies for the sake of enhancing its tolerance to $\mathrm{CO}$ poisoning, a reaction of critical issue to liquid fuel cells. Furthermore, several deposition parameters can influence the structure and properties of the deposited materials. Thus, it is of utmost importance to understand how the deposition conditions impact on the electrocatalytic response of the resulting materials. In this work, our attention was focused on the influence of the background pressure in the PLD deposition chamber. For this, $\mathrm{Pt}$ was synthesized under vacuum and in various pressures of He atmosphere.

These aforesaid nanostructures were then characterized in sulphuric acid solution for their electroactive properties. The CO poisoning tolerance was studied by continuous cycling in the under potential deposited hydrogen $\left(\mathrm{H}_{\text {upd }}\right)$ potential region in a CO saturated electrolyte. These experiments were conducted in a dual thin layer flow electrochemical cell that mimics fluidic fuel cells.

\section{Experimental}

2.1. Catalyst Preparation. The Pt catalysts were deposited by PLD by means of a pulsed $\mathrm{KrF}$ excimer laser $(\lambda=248 \mathrm{~nm})$ with a pulse width of $17 \mathrm{~ns}$ and at a repetition rate of 50 Hz. Pure platinum (99.99\%, Kurt J. Lesker Co.) targets were used. The target was moved continuously across the laser beam via a dual rotation and translation motion to obtain a uniform ablation over the entire target surfaces. Prior to deposition, the chamber was evacuated by means of a turbo pump $\left(4 \times 10^{-5}\right.$ Torr $)$. Helium was then introduced in the deposited chamber. In this study, Pt samples were prepared either under vacuum denoted by $\mathrm{Pt}_{V}$ or in the presence of He gas at various background pressure of 1, 2, 3, 4 to 5 Torr and will be denoted by $\mathrm{Pt}_{1 \mathrm{~T}}, \mathrm{Pt}_{2 \mathrm{~T}}, \mathrm{Pt}_{3 \mathrm{~T}}, \mathrm{Pt}_{4 \mathrm{~T}}$, and $\mathrm{Pt}_{5 \mathrm{~T}}$ (where $\mathrm{T}$ stands for Torr), respectively, or $\mathrm{Pt}_{x \mathrm{~T}}$ when describing all Pt samples. In all cases, the substrate-to-target distance was fixed at $5 \mathrm{~cm}$. The substrates consisted of disks made of graphite (99.997\%, $\varnothing=5 \mathrm{~mm}$, Goodfellow Corp.). The Pt loading as measured by thermogravimetric analysis (TGA) was about $0.64 \mathrm{mg} / \mathrm{cm}^{2}$ for all the samples.

2.2. Characterization. The surface morphology of the asprepared samples was examined by means of a scanning electron microscope (SEM, JEOL, JSM-6300F apparatus) and operated at an accelerating voltage of $10 \mathrm{kV}$ and a transmission electron microscopy (TEM, JEOL, JEM-2100F) operating at $200 \mathrm{kV}$.

X-ray photoelectron spectroscopy (XPS) measurements were performed using a VG Escalab 220i-XL equipped with an $\mathrm{Mg} \mathrm{K} \alpha$ source $(1253.6 \mathrm{eV})$. The anode was operated at $10 \mathrm{kV}$ and $20 \mathrm{~mA}$. The pass energy of the analyzer was fixed at $20 \mathrm{eV}$. All samples were analyzed with a spot size of $250 \times 1000 \mu \mathrm{m}$ located approximately in the center of the sample. A survey spectra ranging from 0 to $1000 \mathrm{eV}$ was first acquired, and then higher resolution multiplex scan spectra ( $\mathrm{Pt} 4 \mathrm{f}, \mathrm{O} 1 \mathrm{~s}$, and $\mathrm{C} 1$ s core levels) were obtained. Quantification of the elements was performed with CasaXPS software (Casa Software Ltd.) by fitting the core level spectra after a Shirley background removal. The metallic components of the $\mathrm{Pt} 4 \mathrm{f}$ region were fitted using a Gaussian/Lorentzian asymmetrically modified line shape, while a Gaussian/Lorentzian line shape was used to fit the other components. The $\mathrm{C} 1 \mathrm{~s}$ core level peak at $284.6 \mathrm{eV}$, resulting from hydrocarbon contaminants at the surface, was used as an internal reference. All spectra have been recalibrated with respect to the $\mathrm{C} 1 \mathrm{~s}$ core level peak of adventitious carbon contamination.

The crystalline structure of all samples was determined by X-ray diffraction (XRD) using Bruker D8 Advance diffractometer equipped with a $\mathrm{Cu} \mathrm{K} \alpha$ source. The diffractometer was operated at $40 \mathrm{kV}$ and $40 \mathrm{~mA}$. All diffractograms were acquired in the $\theta-2 \theta$ scan mode with an angular step size of $2 \theta$ of $0.04^{\circ}$ and an acquisition time of $20 \mathrm{~s}$ by step.

2.3. Electrochemical Measurements. The electrochemical properties of thus PLD-synthesized Pt thin films were studied by performing cyclic voltammetry in a dual thin layer flow cell. The exposed geometric area of the Pt thin films electrode is $0.2 \mathrm{~cm}^{2}$. The electrolyte inlet capillary was located in the center of the cell body, surrounded by four outlet capillaries connecting to the second compartment and cell exhaust. This geometry enabled a radial laminar electrolyte flow over the working electrode surface, driven by an automated microsyringe (Kd Scientific) (electrolyte flow rate of $5 \mu \mathrm{l} / \mathrm{s}$ ). Two Pt wires served as counter electrodes which are connected by an external $1 \mathrm{M} \Omega$ resistance, an $\mathrm{Ag} / \mathrm{AgCl}$ electrode was used as a reference electrode which was connected to the outlet of the cell. The electrode potential was controlled using an EC Epsilon Biopotentiostat (Bioanalytical Systems, InC.). All potentials in this study are referenced to the potential of the reversible hydrogen electrode (RHE).

The characteristic of Pt surface electrochemistry was studied by classical cyclic voltammetry in the potential range from -0.05 to $1.4 \mathrm{~V}$ at a potential scan rate of $50 \mathrm{mV} / \mathrm{s}$ under a continuous flow of Ar-saturated $0.5 \mathrm{M} \mathrm{H}_{2} \mathrm{SO}_{4}$ solution.

The Pt tolerance towards carbon monoxide was investigated by recording CO stripping curves after the Pt surface was pre-adsorbed with $\mathrm{CO}$ for at least $30 \mathrm{~min}$ at a potential of $0.2 \mathrm{~V} / \mathrm{RHE}$ from a CO-saturated electrolyte. Subsequently the electrolyte supply was switched to $\mathrm{CO}$-free $0.5 \mathrm{M} \mathrm{H}_{2} \mathrm{SO}_{4}$ solution. Stripping curves are recorded with a scan rate of $50 \mathrm{mV} / \mathrm{s}$ and the potential limit was set at $1.4 \mathrm{~V} / \mathrm{RHE}$ to guarantee the complete oxidation of the $\mathrm{CO}$ adlayer. A second cycle from -0.05 to $1.4 \mathrm{~V}$ was subsequently recorded in order to verify the complete oxidation of $\mathrm{CO}$ from the surface.

\section{Results and Discussion}

SEM images of Figure 1 show the remarkable differences in the morphology between the PLD-synthesized Pt under vacuum (Figure 1(a)) and those under increasing He background pressures (Figures $1(\mathrm{~b})-1(\mathrm{f})) . \mathrm{Pt}_{V}$ is a dense and smooth film with few scattered particles at its surface. On the other hand, samples prepared under He gas display a very 


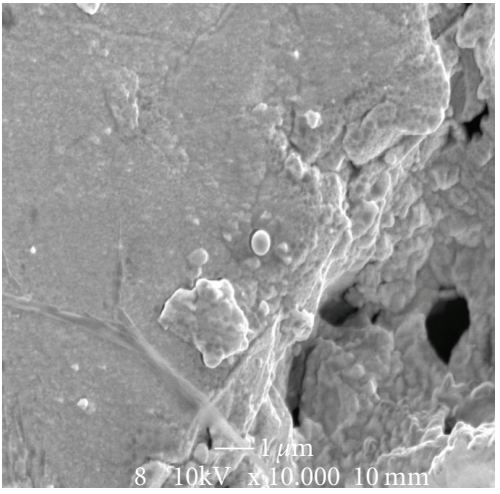

(a)

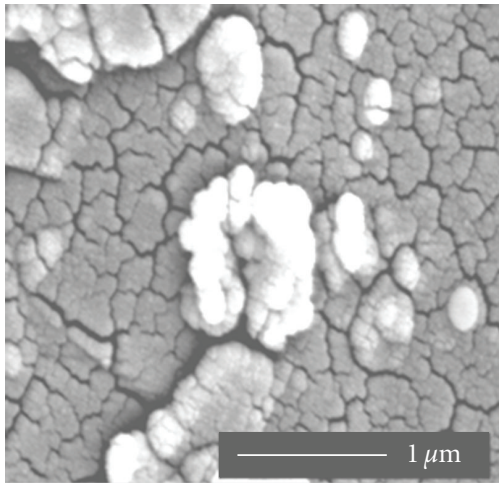

(d)

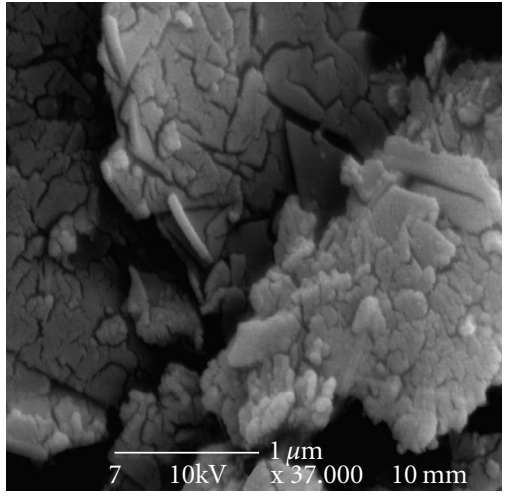

(b)

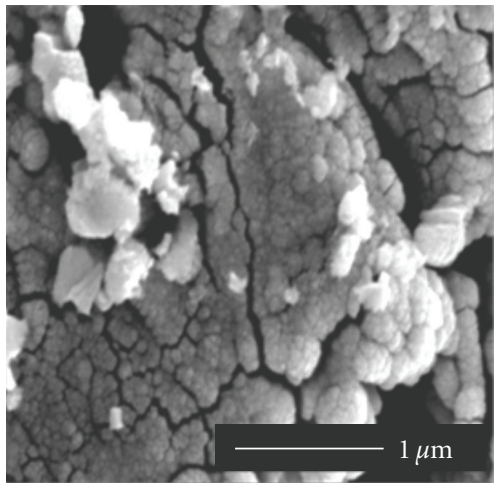

(e)

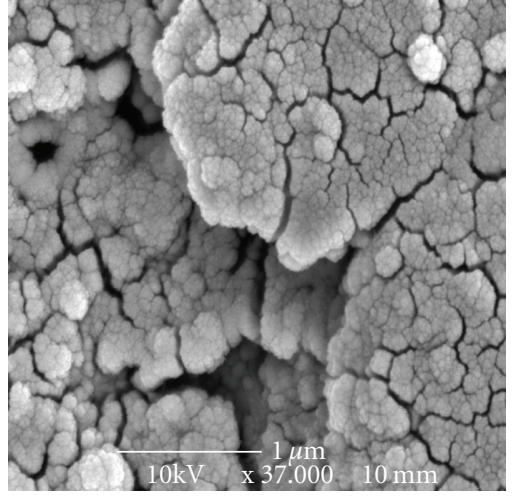

(c)

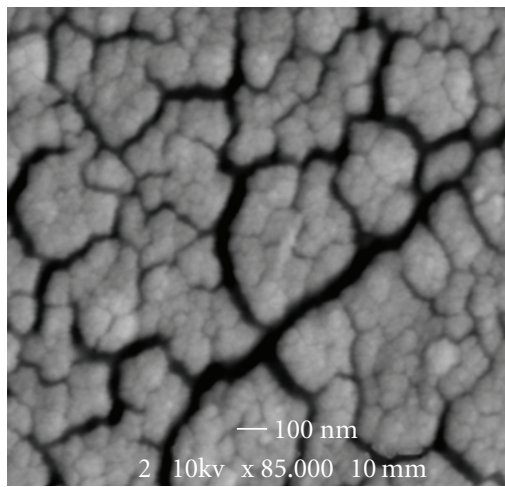

(f)

Figure 1: Electron microscopy analyses of Pt films deposited by PLD: SEM images of (a) $\mathrm{Pt}_{V}$, (b) $\mathrm{Pt}_{1 \mathrm{~T}}$, (c) $\mathrm{Pt}_{2 \mathrm{~T}}$, (d) $\mathrm{Pt}_{3 \mathrm{~T}}$, (e) $\mathrm{Pt}_{4 \mathrm{~T}}$ and (f) and $\mathrm{Pt}_{5 \mathrm{~T}}$.

rough surface with the Pt deposit appearing as an ensemble of agglomerated particles.

Typical TEM and HR-TEM image of Pt films prepared under 5 Torr of He background pressure is shown in Figures 2 (a) and 2(b), respectively. The crystallographic orientation was studied by recording the Selected Area Electron Diffraction (SAED) patterns (Figure 2(c)) demonstrates the polycrystalline nature of the Pt deposit. The crystal lattice fringes of Pt is revealed as the lattice planes of (111), (200) (220) and (311). The particles size distribution show quite a narrow particles distribution with most of the particles having a diameter below $2 \pm 0.8 \mathrm{~nm}$ (Figure $2(\mathrm{~d})$ ).

The XRD patterns of Pt films deposited in vacuum and under various pressures of $\mathrm{He}$ are shown in Figure 3. For reference, the XRD pattern of the graphitic carbon substrate is also shown on the figure. The most important diffraction peaks of the substrate occur at $2 \theta=42.2^{\circ}, 44.3^{\circ}, 50.4^{\circ}$, and $53.9^{\circ}$. At Pt synthesized under vacuum, the XRD pattern display peaks of $\mathrm{Pt}$ are at $39.7^{\circ}, 44.5^{\circ}, 67.5^{\circ}$ and $81.2^{\circ}$ corresponding to (111), (200), (220), and (311), respectively. At Pt films deposited under He background pressure, only the (111) diffraction peak remains visible while the other diffraction peaks are barely seen. It can be however noted that the intensities of the diffraction peaks decreased when the pressure of He increased, which might be explained by the fact that at high pressures, the Pt kinetic energy decreases and this reflects the fact that the surface mobility of Pt species is decreased when the films are made from a plasma plume with low kinetic energies. In addition, XRD pattern showed also a variation in width of peaks that increases when pressure of He increases, which indicates that the crystallite size becomes smaller. Since the Pt (111) was the most intense diffraction peak it was thus chosen to evaluate the lattice parameter of the fcc phase. A lattice parameter of $3.91 \AA$ was obtained and was found unchanged for Pt films whether those deposited under vacuum or those made under various He background pressures.

High-resolution XPS Pt $4 \mathrm{f}$ core level spectra of the various Pt deposits are reported in Figure 4. The Pt4f core level spectrum displays two peaks whose maximum intensities are located between 70 and $78 \mathrm{eV}$ binding energy range. The binding energy difference ( $\Delta E$ bind) varies between 3.29 and $3.34 \mathrm{eV}$ between these two maxima is that expected from $\mathrm{Pt} 4 \mathrm{f}_{7 / 2}$ and $\mathrm{Pt}_{4} \mathrm{f}_{5 / 2}$ core level peaks. The position of these two peaks is consistent with Pt being in a metallic state [7]. All survey scans (not shown) presented peaks only for $\mathrm{Pt}, \mathrm{C}$ and $\mathrm{O}$, indicating a surface clean of any contaminants other than adventitious carbon and adsorbed water.

The characteristic surface electrochemistry of PLDdeposited Pt films was studied by cyclic voltammetry (CV). Figure 5 exemplifies a $\mathrm{CV}$ recorded in a $0.5 \mathrm{M} \mathrm{H}_{2} \mathrm{SO}_{4}$ deaerated solution for a $\mathrm{Pt}_{5 \mathrm{~T}}$ film. The sample exhibited the 


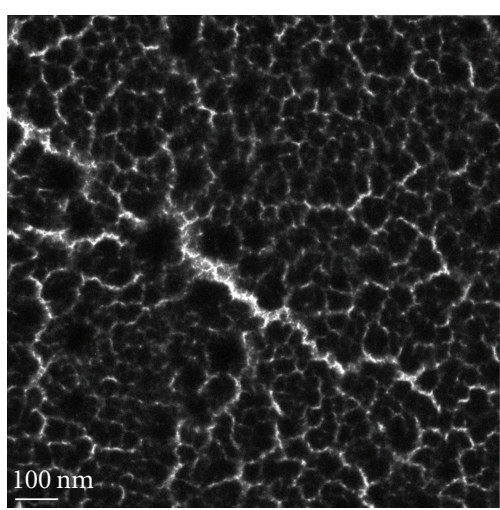

(a)

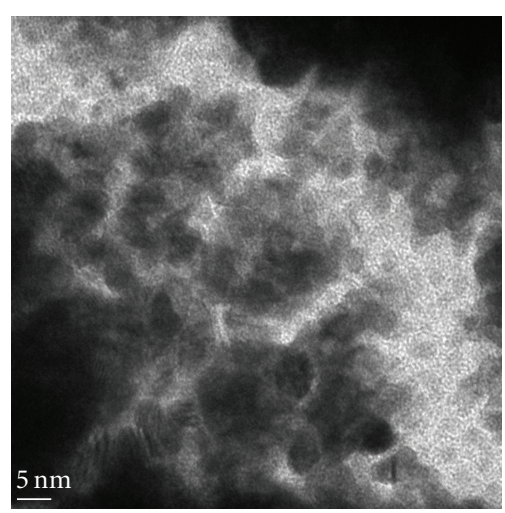

(b)

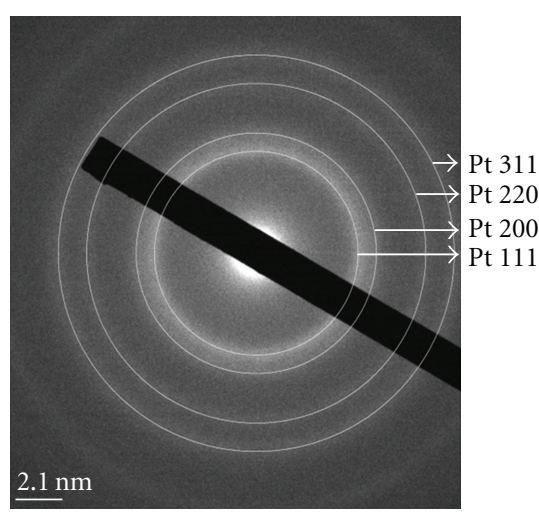

(c)

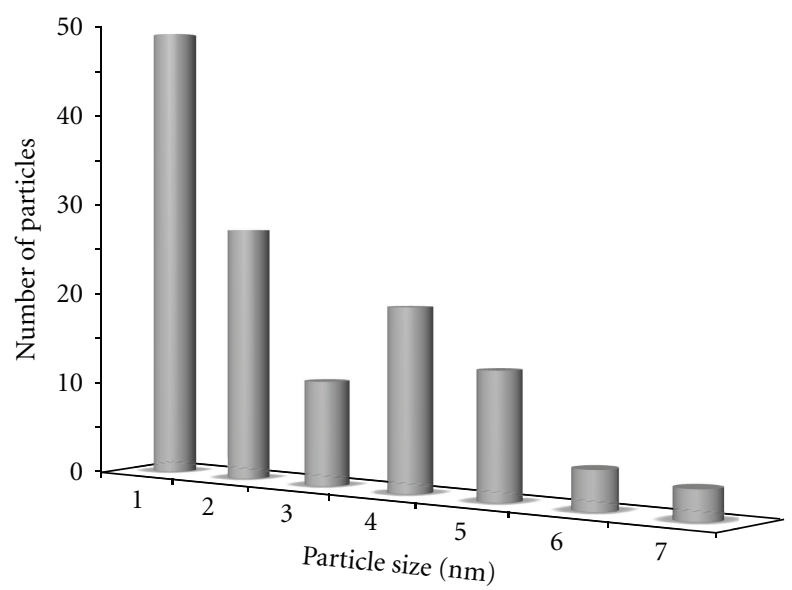

(d)

FIGURE 2: Electron microscopy analyses: typical (a) TEM, (b) HR-TEM, (c) SAED patterns, and (d) particles size distribution of Pt films deposited by PLD under 5 Torr of He background pressure.

very well-known hydrogen adsorption $\left(\mathrm{H}_{\mathrm{ads}}\right)$ and desorption $\left(\mathrm{H}_{\mathrm{des}}\right)$ regions in the potential region of ca. -0.05 to $0.4 \mathrm{~V}$ $[8,9]$. It has to be noted that peaks characteristics of $\mathrm{H}_{\mathrm{ad}} / \mathrm{H}_{\mathrm{des}}$ became progressively resolved and their currents higher as the He background pressure increased, which illustrates the better utilisation of Pt.

To measure the effect of the morphology on the electrochemical activity of Pt catalysts, the electroactive surface area (ESA) was determined by integrating the charge in the hydrogen adsorption region of the voltammograms, corrected for the double-layer current by back extrapolation of the current from the double layer region, using a conversion factor of $210 \mu \mathrm{C} \mathrm{cm}^{-2}[10,11]$. Thus calculated ESA plotted as function of the pressure synthesis is also shown in Figure 6. It can be seen that $\mathrm{Pt}_{x T}$ films exhibited ESA higher than that of $\mathrm{Pt}_{V}$. One can further see that the ESA increases linearly with the increase of background pressure of He. Such correlation is being reported here for the first time and clearly demonstrates that despite the same loading of Pt and the same particle size distribution, the morphology plays a non trivial role in the electrocatalytic activity of Pt. To further understand this effect, we calculated the roughness factor (RF), which was estimated by dividing the ESA by the geometric area of the electrode $\left(0.2 \mathrm{~cm}^{2}\right)$ and the results are shown in Figure 6. It can be observed that $\mathrm{Pt}_{x T}$ deposits are rougher than $\mathrm{Pt}_{V}$, which is in agreement with SEM observations (Figure 1). Secondly, increasing He pressure provided rougher deposits that exhibit higher electrocatalytic activity.

Figure 7 represents $\mathrm{CO}_{\mathrm{ads}}$ stripping voltammograms recorded at $\mathrm{Pt}_{5 \mathrm{~T}}$ electrode. The voltammograms display a $\mathrm{CO}_{\text {ads }}$ stripping peak located at ca. $0.78 \mathrm{~V}$ versus $\mathrm{RHE}$ as expected $[12,13]$. The hydrogen adsorption features are clearly observed during the reverse and successive scans. In fact the hydrogen profile is identical to that recorded prior to $\mathrm{CO}$ adsorption. This feature illustrates the stability of the samples during the process. On the other hand, for $\mathrm{Pt}_{V}$, $\mathrm{H}_{\mathrm{ad}} / \mathrm{H}_{\text {des }}$ peaks were not restored after stripping the adsorbed CO. In addition as the extent of roughness increased, the amplitude of the CO stripping peak augmented, and while its position was at $0.87 \mathrm{~V}$ for $\mathrm{Pt}_{V}$, it stayed constant at around $0.78 \mathrm{~V}$ for $\mathrm{Pt}_{1-5 \mathrm{~T}}$ films (Figure 8). The position of $\mathrm{CO}$ stripping peak for $\mathrm{Pt}_{V}$ is close to $0.83 \mathrm{~V}$ a value observed for smooth polycrystalline Pt foil [14]. Apparently, adsorption and electrocatalytic properties of $\mathrm{Pt}_{V}$ sample approach those of bulk material. The coulometric charge under the 


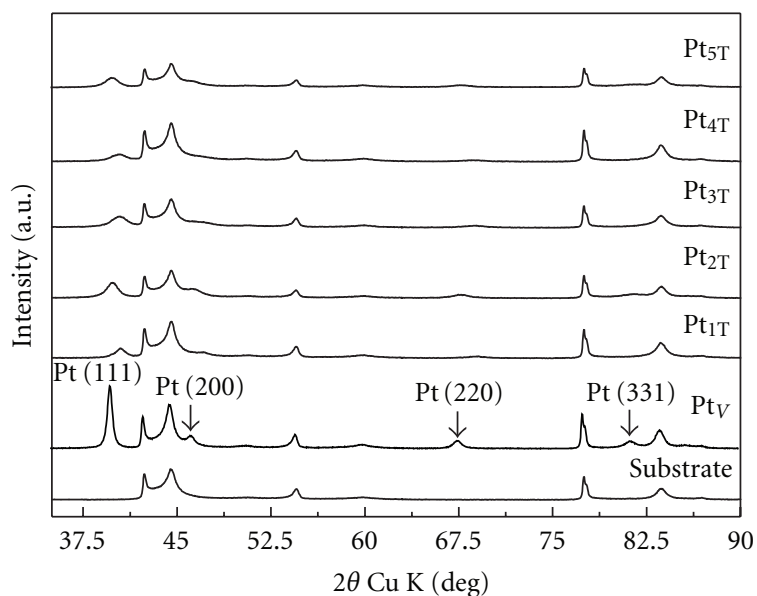

FIgURE 3: X-ray diffraction patterns of Pt films deposited by PLD under various conditions of background gas pressure as indicated in the figure. For reference, the XRD pattern of the graphite substrate is also reported on the figure.

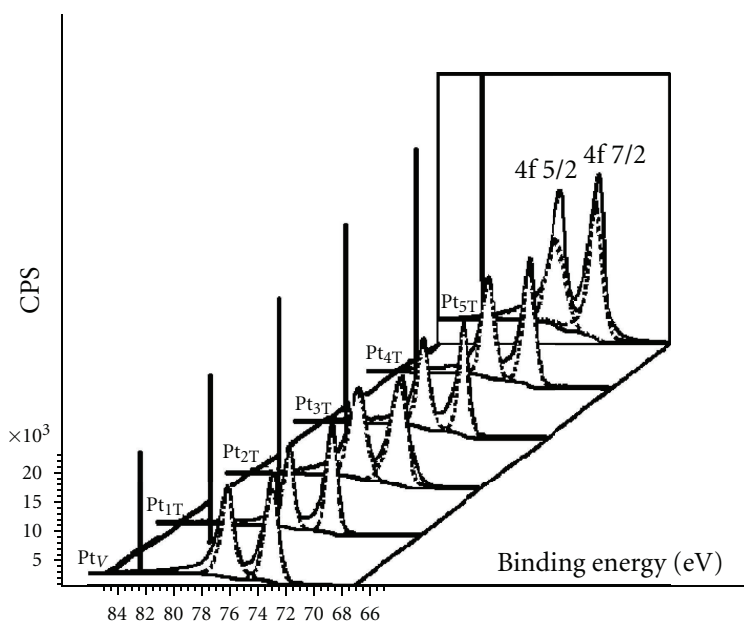

Figure 4: X-ray photoelectron spectra of Pt4f core level peaks of Pt films deposited by PLD under various conditions of background gas pressure as indicated in the figure.

stripping peak $\left(Q_{\text {strip }}\right)$ required for $\mathrm{CO}_{\mathrm{ads}}$ electrooxidation corresponding to $\mathrm{Pt}_{\mathrm{xT}}$ films increased from $\mathrm{Pt}_{1 \mathrm{~T}}$ to $\mathrm{Pt}_{2 \mathrm{~T}}$ levelled off up to $\mathrm{Pt}_{4 \mathrm{~T}}$ and then increased again to $\mathrm{Pt}_{5 \mathrm{~T}}$ (Figure 9).

Next, the net charge due to oxidation and desorption of the $\mathrm{CO}$ adlayer was estimated following the strategy of Gomez et al. in [15]

$$
Q_{C O}^{\text {net }}=Q_{\text {strip }}-\left|Q_{T}\right|-\int_{E_{\mathrm{T}}}^{E_{+}} \frac{j}{v} \mathrm{~d} E,
$$

where $Q_{T}$ is the reduction charge density displaced by $\mathrm{CO}$ adsorption at a certain potential $\left(E_{T}\right)$ in the double layer region and it is linked to the adsorption of anions on the multilayer with charge transfer. $E_{+}$is the positive potential limit chosen to make the peak integration, $j$ is the voltammetric current density and, finally, $v$ is the potential

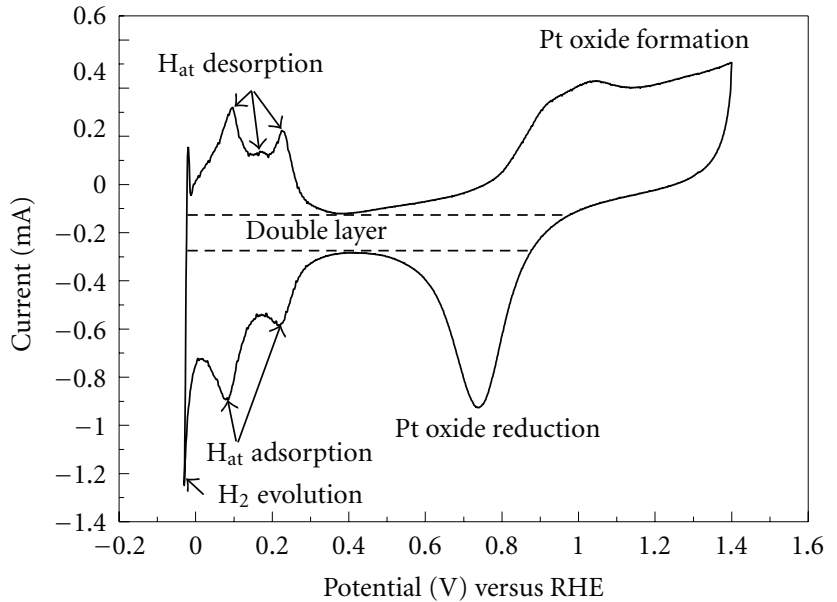

Figure 5: Cyclic voltammetry in a deaerated base $0.5 \mathrm{M} \mathrm{H}_{2} \mathrm{SO}_{4}$ solution at $\mathrm{Pt}_{5 \mathrm{~T}}$ electrodes at a scan rate of $50 \mathrm{mV} / \mathrm{s}$.

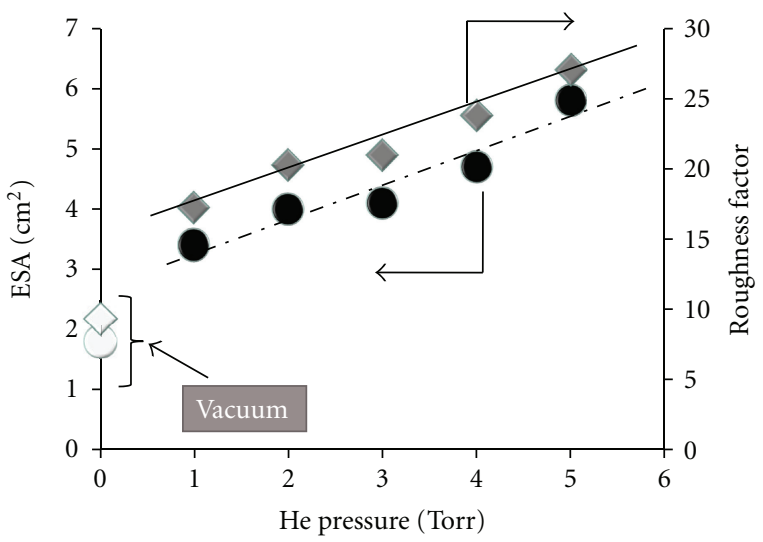

FIGURE 6: Variation of the electroactive surface area (circles) and the roughness factor (diamonds) as function of the PLD deposition background gas pressure.

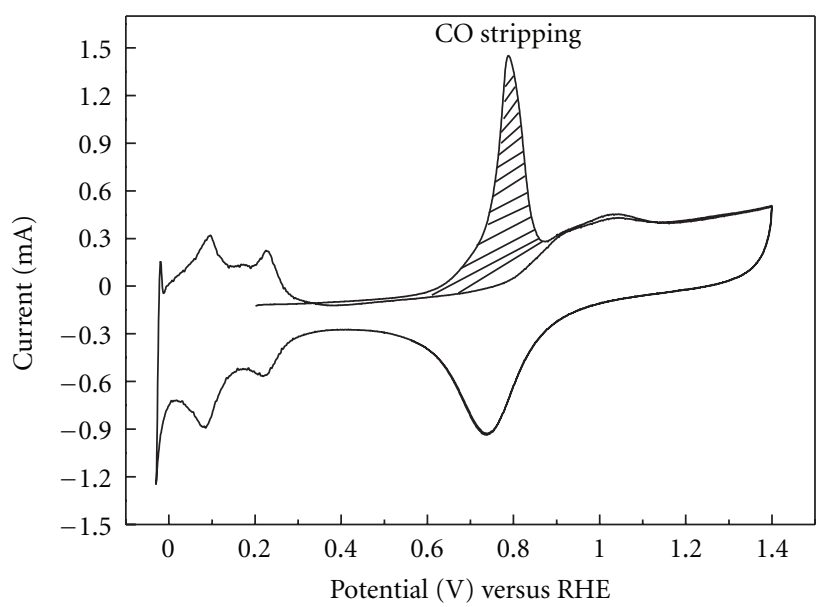

Figure 7: Base and CO stripping voltammograms for a $\mathrm{Pt}_{5 \mathrm{~T}}$ electrode in $0.5 \mathrm{M} \mathrm{H}_{2} \mathrm{SO}_{4}$ at a scan rate of $50 \mathrm{mV} / \mathrm{s}$. 


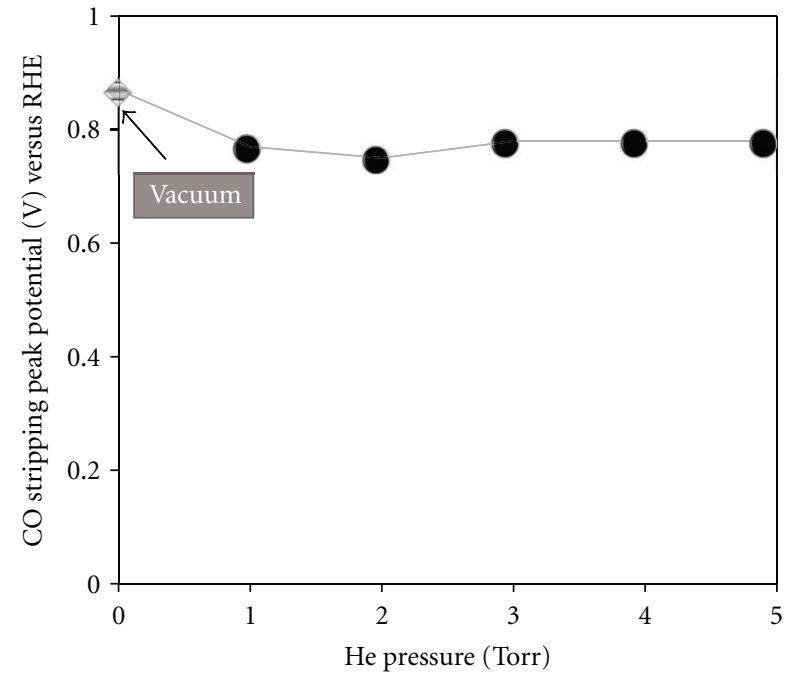

FIGURE 8: Variation of the CO stripping peak potential as function of the PLD deposition background gas pressure.

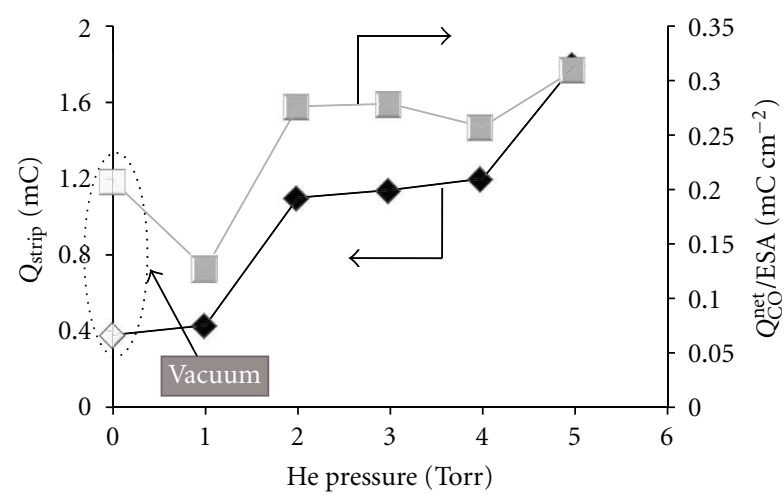

FIGURE 9: Variation of the coulometric charge under the stripping peak $\left(Q_{\text {strip }}\right)$ required for $\mathrm{CO}_{\mathrm{ads}}$ electrooxidation (diamonds) and the net charge due to oxidation and desorption of the $\mathrm{CO}$ adlayer (squares) as function of the PLD deposition background gas pressure.

sweep rate in cyclic voltammetry. The integral term on the right-hand side of the preceding equation equals the total integrated charge density between the potential at which the displacement was performed and $E_{+}$. It is ascribed to double layer charging and oxide formation. Thus calculated $Q_{C O}^{\text {net }}$ normalised to the ESA is also reported in Figure 9, which shows a value as high as $350 \mu \mathrm{C} \mathrm{cm}^{-2}$ displayed by $\mathrm{Pt}_{5 \mathrm{~T}}$ electrode.

The corresponding $\mathrm{CO}$ coverage, $\theta_{\mathrm{CO}}$, is calculated through the following expression [15]:

$$
\theta_{\mathrm{CO}}=\frac{Q_{\mathrm{CO}}^{\text {net }}}{n 210},
$$

where $n$ is the number of electrons exchanged per $\mathrm{CO}$ molecule during its oxidation $(n=2)$ and $210 \mu \mathrm{C} \mathrm{cm}^{-2}$ as the charge density for a process involving one electron per $\mathrm{Pt}$ surface site. The estimated value $\theta_{\mathrm{CO}}$ after the first potential

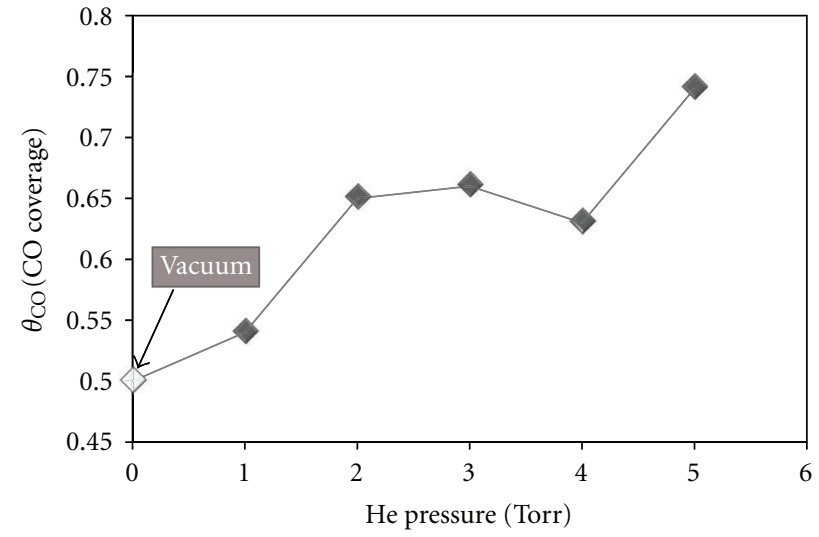

FIgURe 10: Variation of the CO coverage as function of the PLD deposition background gas pressure.

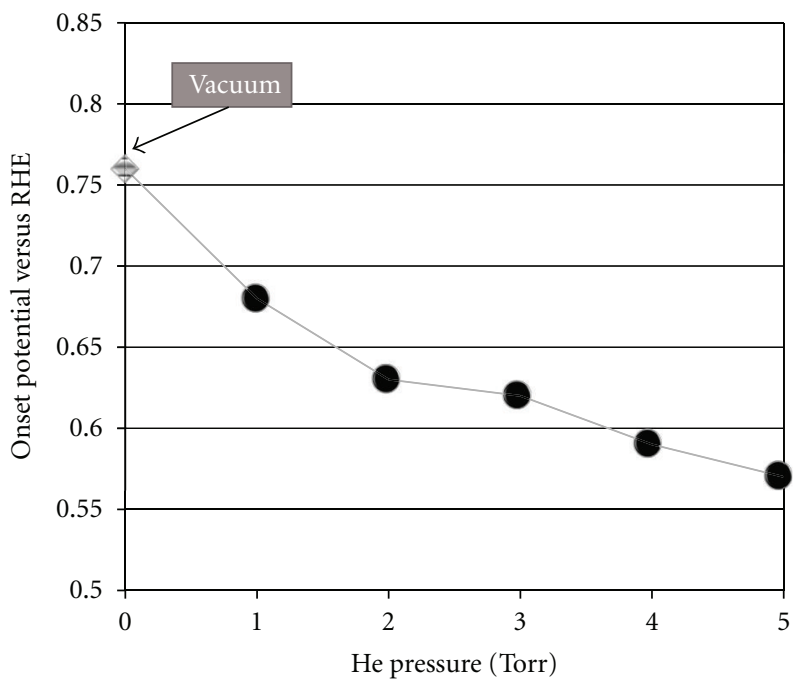

FIGURE 11: Variation of the onset potential for CO oxidation as function of the PLD deposition background gas pressure.

cycle for all Pt films is reported in (Figure 10) as function of the gas background pressure. One can see that while CO coverage increased with He pressure due to the increased surface roughness, cycling voltammetry results (Figure 7) demonstrate a complete removal of adsorbed $\mathrm{CO}$ since no stripping peaks were observed during the second scan. Oppositely, $\mathrm{Pt}_{V}$ presented a lower electrocatalytic activity for $\mathrm{CO}$ oxidation for which several potential cycles were required to achieve a complete removal. This further demonstrates the increased electrocatalytic activity of Pt surfaces prepared with $\mathrm{He}$ in the deposition chamber. $\mathrm{Pt}_{5 \mathrm{~T}}$ showed the highest CO coverage of about $75 \%$ because the surface is rougher and offers more active sites compared to other Pt samples.

The onset potential of the $\mathrm{CO}$ electrooxidation reaction is a further important parameter for the designing of $\mathrm{CO}$ tolerant electrocatalysts. The $j-E$ plots recorded both on the $\mathrm{Pt}_{V}$ and $\mathrm{Pt}_{\mathrm{xT}}$ electrocatalysts during the $\mathrm{CO}$ oxidation process are depicted in Figure 11. Here too, the onset 
potential is obviously morphology sensitive for the oxidation of CO. It is notable that $\mathrm{CO}$ oxidation on Pt agglomerates occurs at lower overpotentials than that on smooth film $\left(\mathrm{Pt}_{V}\right)$. The most remarkable low onset potential was obtained with $\mathrm{Pt}_{5 \mathrm{~T}}$ electrode with a value of about $0.57 \mathrm{~V}$ that is $190 \mathrm{mV}$ negative than that observed at $\mathrm{Pt}_{V}(0.76 \mathrm{~V})$.

\section{Conclusions}

The pulsed laser deposition has been successfully used to synthesize Pt nanostructured films of different morphologies. Several results are reported here for the first time:

It was found that $\mathrm{Pt}$ deposited under vacuum was very smooth and dense. On the other hand Pt deposited under He background pressure was rough and made of particles agglomerates. As the pressure increased, the roughness increased. This led to an enhancement in the electroactive surface area.

As to the CO tolerance of $\mathrm{Pt}$, several conclusions can be drawn:

Although the same amount of $\mathrm{CO}$ was adsorbed at the surfaces of all Pt deposits, the electrochemical CO monolayer oxidation is strongly influenced by the morphology of $\mathrm{Pt}$ catalyst, that is, the rougher the surface, the lower the CO oxidation potential and thus higher resistance to $\mathrm{CO}$ poisoning.

Among the catalysts, $\mathrm{Pt}$ deposited under 5 Torr of He background pressure showed the highest electroactive surface area, and the lowest onset potential of CO oxidation demonstrating an enhancement of the $\mathrm{CO}$ poisoning resistance.

The reason for such enhanced electrocatalytic activity is definitely ascribed to the high roughness of Pt surface. This study further provides a methodology for the proper design of catalysts that might be considered to be developed by the pulsed laser deposition technique.

\section{Acknowledgments}

This work was supported by the Natural Sciences Engineering Research Council of Canada (NSERC), the Fonds Québécois pour la Recherche en Nature et Technologie (FQRNT), and the Centre Québécois sur les Matériaux Fonctionnels (CQMF).

\section{References}

[1] E. Antolini, "Catalysts for direct ethanol fuel cells," Journal of Power Sources, vol. 170, no. 1, pp. 1-12, 2007.

[2] H. Liu, C. Song, L. Zhang, J. Zhang, H. Wang, and D. P. Wilkinson, "A review of anode catalysis in the direct methanol fuel cell," Journal of Power Sources, vol. 155, no. 2, pp. 95-110, 2006.

[3] A. Kabbabi, R. Faure, R. Durand et al., "In situ FTIRS study of the electrocatalytic oxidation of carbon monoxide and methanol at platinum-ruthenium bulk alloy electrodes," Journal of Electroanalytical Chemistry, vol. 444, no. 1, pp. 4153, 1998.

[4] D. B. Chrisey and G. K. Hubler, Eds., Pulsed Laser Deposition of Thin Films, Wiley, New York, NY, USA, 1994.
[5] E. Irissou, B. Le Drogoff, M. Chaker, and D. Guay, "Influence of the expansion dynamics of laser-produced gold plasmas on thin film structure grown in various atmospheres," Journal of Applied Physics, vol. 94, no. 8, pp. 4796-4802, 2003.

[6] R. Dolbec, E. Irissou, M. Chaker, D. Guay, F. Rosei, and M. A. El Khakani, "Growth dynamics of pulsed laser deposited Pt nanoparticles on highly oriented pyrolitic graphite substrates," Physical Review B, vol. 70, no. 20, Article ID 201406, 4 pages, 2004.

[7] C. D. Wagner, W. M. Riggs, L. E. Davis, and J. F. Moulder, Handbook of X-Ray Photoelectronic Spectroscopy, G. E. Muilenberg, Ed., Perkin-Elmer, Eden Prairie, Minn, USA, 1979.

[8] K. Kinoshita, D. R. Ferrier, and P. Stonehart, "Effect of electrolyte environment and Pt crystallite size on hydrogen adsorption-V," Electrochimica Acta, vol. 23, no. 1, pp. 45-54, 1978.

[9] T. J. Schmidt, H. A. Gasteiger, G. D. Stäb, P. M. Urban, D. M. Kolb, and R. J. Behm, "Characterization of high-surface-area electrocatalysts using a rotating disk electrode configuration," Journal of the Electrochemical Society, vol. 145, no. 7, pp. 23542358, 1998.

[10] M. C. Dos Santos and S. A. S. Machado, "Electrochemical deposition of the first $\mathrm{Cd}$ monolayer on polycrystalline Pt and Au electrodes. An Upd study," Journal of the Brazilian Chemical Society, vol. 9, no. 3, pp. 211-218, 1998.

[11] K. Yamamoto, D. M. Kolb, R. Kötz, and G. Lehmpfuhl, "Hydrogen adsorption and oxide formation on platinum single crystal electrodes," Journal of Electroanalytical Chemistry, vol. 96, no. 2, pp. 233-239, 1979.

[12] J. Jiang and A. Kucernak, "Electrooxidation of small organic molecules on mesoporous precious metal catalysts I: CO and methanol on platinum," Journal of Electroanalytical Chemistry, vol. 533, no. 1-2, pp. 153-165, 2002.

[13] F. Maillard, M. Eikerling, O. V. Cherstiouk, S. Schreier, E. Savinova, and U. Stimming, "Size effects on reactivity of Pt nanoparticles in CO monolayer oxidation: the role of surface mobility," Faraday Discussions, vol. 125, pp. 357-377, 2004.

[14] A. Ponrouch, S. Garbarino, and D. Guay, "Effect of the nanostructure on the CO poisoning rate of platinum," Electrochemistry Communications, vol. 11, no. 4, pp. 834-837, 2009.

[15] R. Gómez, A. Rodes, J. M. Pérez, J. M. Feliu, and A. Aldaz, "Electrochemical and in situ FTIRS studies of the CO adsorption at palladium and rhodium multilayers deposited on platinum single crystal surfaces II. Pt(100) substrate," Surface Science, vol. 344, no. 1-2, pp. 85-97, 1995. 